\title{
Vitamin B12 deficiency among adult diabetic patients in Uganda: relation to glycaemic control and haemoglobin concentration
}

\author{
George Patrick Akabwai ${ }^{1 *}$, Davis Kibirige ${ }^{2}$, Levi Mugenyi ${ }^{3}$, Mark Kaddu' ${ }^{1}$ Christopher Opio ${ }^{1}$, Rejani Lalitha', \\ Edrisa Mutebii ${ }^{4}$ and Martha Sajatovic ${ }^{5}$
}

\begin{abstract}
Background: Vitamin B12 deficiency is highly prevalent among adult individuals with diabetes yet screening is infrequent in Uganda. There are currently no published data regarding the prevalence of vitamin B12 deficiency and its associated factors among adult individuals with diabetes in sub-Saharan Africa. This study aimed at describing the prevalence and factors associated with vitamin B12 deficiency among this patient population in a resource constrained setting in sub-Saharan Africa.

Methods: In this cross-sectional study, 280 eligible study participants attending the outpatient diabetic clinic at Mulago national referral and teaching hospital in Kampala, Uganda were enrolled. Their socio-demographic, clinical and laboratory data was collected using a pre-tested questionnaire.

Results: The majority of the study participants were female (68.9\%), with a median age of 50 (IQR: 40-58) years. The mean (SD) serum vitamin B12 levels was $472.0(16.4) \mathrm{pg} / \mathrm{ml}$. The prevalence of vitamin B12 deficiency was 10. $7 \%$. Hemoglobin level < $12 \mathrm{~g} / \mathrm{dl}$ (AOR 3.38; $95 \% \mathrm{Cl} 1.38-8.32, p$ value $=0.008)$ and glycated hemoglobin $\geq 7 \%$ (AOR 3.29; 1.44-7.51, $p$ value $=0.005$ ) were associated with vitamin B12 deficiency.

Conclusions: Vitamin B12 deficiency is prevalent in approximately 1 in 10 of adult individuals with diabetes in Uganda. We recommend screening for vitamin B12 deficiency among diabetic patients in Uganda especially those with low hemoglobin concentrations and glycated hemoglobin levels $\geq 7 \%$.
\end{abstract}

Keywords: Vitamin B12 deficiency, Adults, Black, Individuals with diabetes, Africa, Uganda

\section{Background}

Vitamin B12 or cobalamin is a water soluble vitamin that plays a very essential role in DNA synthesis, optimal haemopoesis and neurological function [1]. Several studies have unequivocally demonstrated that vitamin B12 deficiency is highly prevalent in adult diabetic patients [2-4]. The most notable risk factor associated with vitamin B12 deficiency in adult individuals with diabetes in clinical practice is long term and high dose metformin therapy [4-6]. Clinically overt and untreated vitamin B12 deficiency has

\footnotetext{
* Correspondence: gpakabwai@yahoo.com

'Department of Medicine, Makerere University College of Health Sciences, P.O.BOX 7062, Kampala, Uganda

Full list of author information is available at the end of the article
}

been associated with disabling sensory polyneuropathy which mimics diabetic neuropathy, anaemia, depression, cognitive dysfunction $[1,7,8]$.

Despite the above recognised clinical conditions associated with vitamin B12 deficiency and its high frequency in adult individuals with diabetes, there are no global guidelines recommending routine assessment of serum vitamin B12 levels. In sub Saharan Africa (SSA), a region with a high frequency of nutritional deficiencies, there is a dearth of data on the burden and predictors of vitamin B12 deficiency in adult individuals with diabetes.

We therefore sought to determine the prevalence and associated factors of vitamin B12 deficiency in 280 adult individuals with diabetes attending the outpatient diabetic 
clinic at Mulago national referral and teaching hospital in Kampala, Uganda.

\section{Methods}

Between 1st May and 31st September 2014, we performed a cross sectional study to assess vitamin B12 levels and related clinical factors in the outpatient diabetic clinic of Mulago national referral and teaching hospital, Kampala Uganda. The clinic is run every Wednesday and an average of 80 adult patients is reviewed on each clinic day. Patients enrolled into the study were: ambulatory with documented evidence of DM and had regularly been attending the clinic for at least the past 6 months, aged $\geq 18$ years and had offered informed consent. Patients on vitamin B12 replacement therapy or multi vitamin supplementation were excluded.

\section{Sample size and sampling technique}

A consecutive sampling method was used during the recruitment process of the eligible patients until the desired sample size of 280 was obtained. Using the Kish-Leslie formula (1995) of $n=\mathrm{Z}^{2} \mathrm{Pq} / \mathrm{d}^{2}$ ( $n=$ Sample size, $Z=1.96$, the normal value corresponding to the $95 \%$ confidence interval, $P=0.22$-prevalence of vitamin B12 deficiency of $22 \%$ from a study by Pflipsen $M$ et al. [2] in adult individuals with diabetes, $q=1-p$ and $d=5 \%$, the desired precision of estimation), a sample size of a minimum of 264 patients was obtained. We increased the sample size to 280 patients.

\section{Data collection}

A questionnaire in English or Luganda, the commonly spoken local dialect in the region was administered to the study participants. The translation of the questionnaires from English to Luganda was done by someone fluent in the language and adept in questionnaire translation. The translated questionnaires were pre tested to ensure validity of the results to be obtained.

Information obtained included key socio-demographic characteristics like age, gender, employment and education status, clinical signs and symptoms related to vitamin B12 deficiency, past medical and drug history, family history of DM and hypertension and lifestyle and social activities such as alcohol intake and smoking. Participants' weight in kilograms $(\mathrm{kg})$ and height in metres (m) were measured using a calibrated weight scale and height board respectively and their body mass indexes (BMI) calculated using the formula below; $\mathrm{BMI}=\mathrm{kg} / \mathrm{m}^{2}$.

\section{Laboratory analysis}

Six millilitres of blood were drawn by an experienced laboratory technician and sent for analysis. The complete blood count $(\mathrm{CBC})$ and peripheral film comment were done by an experienced haematologist in the haematology laboratory of Mulago hospital. Serum vitamin B12 levels, the outcome variable, glycated haemoglobin (HbA1c), fasting lipid profile, renal and liver function tests were analysed from the clinical chemistry laboratory of Mulago hospital using the Roche diagnostics Elecsys@ immunoassays. The main outcome of this study was vitamin B12 deficiency defined as serum vitamin B12 serum levels $<200 \mathrm{pg} / \mathrm{ml}$. Borderline vitamin B12 deficiency and normal vitamin B12 levels were defined as vitamin B12 levels between 200 and $300 \mathrm{pg} / \mathrm{ml}$ and $>300 \mathrm{pg} / \mathrm{ml}$ respectively.

\section{Statistical analysis}

Pre-coded data were entered using EPI-DATA 3.1 and were exported to statistical package, STATA 10, for statistical analysis with the help of a statistician. Age was presented as median as this was not normally distributed and grouped onto age categories for further analysis. Categorical variables were analyzed and presented as frequencies and percentages. They were compared using the chi-square and Fisher's exact tests as appropriate. At bivariable analysis, variables with a $p$ vaues $\leq 0.2$ were subjected to multivariable analysis using a logistic regression and model building done using a likelihood ratio test.

The prevalence of vitamin B12 deficiency was expressed as the proportion of study participants with serum vitamin B12 levels $<200 \mathrm{pg} / \mathrm{ml}$ divided by the total number of participants enrolled into the study. A $p$-value of 0.05 was considered statistically significant.

\section{Results}

\section{Socio demographic and clinical characteristics of study participants}

Of the 280 study participants enrolled into the study, there was a female predominance (193, $68.9 \%)$. The median age (IQR) for the study participants was $50(40-58)$ years. The majority of the study participants were urban dwellers (175, $62.5 \%)$, unemployed (147, $52.7 \%)$ and had attained primary level education $(137,48.9 \%)$ (summarised in Table 1).

The most frequent clinical symptoms were paraesthesias (227, $81.1 \%)$, forgetfulness $(24,8.57 \%)$ and tiredness even after light exertion $(14,5 \%)$. Others included irritability (12, $4.3 \%)$ and gait abnormality (11, $3.9 \%)$. Clinical pallor of the mucous membranes and palmar pigmentation were observed in only $8(2.86 \%)$ and $3(1.1 \%)$ study participants respectively. Hypertension, prior use of proton pump inhibitors (PPIs) and HIV infection were documented in 188 (67\%), 73 (26\%) and 17 (6.1\%) study participants respectively. Family history of hypertension and diabetes was reported in 200 (71.4\%) and 187 (66.8\%) participants respectively. Most participants were type 2 diabetics $(224,81.5 \%)$. 
Table 1 Demographic characteristics of the study participants $(N=280)$

\begin{tabular}{lll}
\hline Characteristic & & $n(\%)$ \\
\hline Age, median (IQR) & Female & $50(18)$ \\
Gender, $n(\%)$ & $193(68.9)$ \\
Address, $n$ (\%) & Rural & $105(37.5)$ \\
Education level, $n$ (\%) & Urban & $175(62.5)$ \\
& None & $31(11.1)$ \\
& Primary & $137(48.9)$ \\
Religion, $n$ (\%) & Secondary & $100(35.7)$ \\
& Post-secondary & $12(4.3)$ \\
& Muslim & $72(25.8)$ \\
Occupation, $n$ (\%) & Catholic & $86(30.8)$ \\
& Anglican & $86(30.8)$ \\
Marital status, $n$ (\%) & Born again & $35(12.5)$ \\
& Employed & $133(47.5)$ \\
& Unemployed & $147(52.5)$ \\
& Married & $156(55.7)$ \\
& Cohabiting & $10(3.6)$ \\
& Single & $28(10.0)$ \\
& Divorced & $41(14.6)$ \\
& Widow/widowed & $45(16.1)$ \\
\hline
\end{tabular}

\section{Vitamin B12 status of the study participants}

The mean (SD) serum vitamin B12 level of the study participants was $472(16.4) \mathrm{pg} / \mathrm{ml}$. Vitamin B12 deficiency, borderline vitamin B12 deficiency and normal vitamin B12 levels were documented in 30 (10.7 \%), 42 (15\%) and 208 (74.3\%) participants respectively. A total of $72(25.7 \%)$ participants had suboptimal vitamin B12 levels, defined as vitamin B 12 levels $<300 \mathrm{pg} / \mathrm{ml}$. All these study participants had never had a serum vitamin B12 measurement performed before.

\section{Socio-demographic and clinical characteristics of the study participants at bivariable analysis}

At bivariable analysis, neither socio-demographic nor clinical characteristics were associated with vitamin B 12 deficiency. (Tables 2 and 3 summarizes the socio-demographic and clinical characteristics of the study participants in association with vitamin B12 levels at bivariable analysis).

\section{Laboratory findings of the study participants at bivariable analysis}

A statistically significant association with vitamin B12 deficiency was observed with hemoglobin concentration $<12 \mathrm{~g} / \mathrm{dl}(p=0.001), \mathrm{WBC}$ counts $>4000$ cells $/ \mathrm{mm}^{3}$ $(p=0.017)$ and glycated hemoglobin $\geq 7 \%(p=0.001)$. Paradoxically, a high mean cell volume $(\mathrm{MCV}) \geq 100$ was infrequent in participants with vitamin B12 deficiency
Table 2 Vitamin B12 deficiency in relation to sociodemographic characteristics at bivariable analysis

\begin{tabular}{lllll}
\hline Characteristic & & $<200 \mathrm{pg} / \mathrm{ml}$ & $\begin{array}{l}\geq 200 \mathrm{pg} / \mathrm{ml} \\
N=30(\%)\end{array}$ & $P$ value \\
& & $4(13.3)$ & $72(28.8)$ & 0.137 \\
\hline Age in years & $<40$ & $18(60.0)$ & $136(54.4)$ & \\
& $40-60$ & $8(26.7)$ & $42(16.8)$ & \\
& $>60$ & $6(20.0)$ & $81(32.4)$ & 0.166 \\
Sex & Male & $24(80.0)$ & $169(67.6)$ & \\
Address & Female & $9(30.0)$ & $96(38.4)$ & 0.369 \\
& Rural & $21(70.0)$ & $154(61.6)$ & \\
Education level & Urban & $19(63.3)$ & $149(59.6)$ & 0.693 \\
& None/primary & $11(36.7)$ & $101(40.4)$ & \\
Religion & Most primary & $7(23.3)$ & $65(26.1)$ & 0.889 \\
& Muslim & $11(36.7)$ & $75(30.1)$ & \\
& Catholic & $9(30.0)$ & $77(30.9)$ & \\
& Anglican & $3(10.0)$ & $32(12.9)$ & \\
& Born-again & & & \\
& & & &
\end{tabular}

(1, $3.4 \%)$. The majority had normal MCV levels (18, $62.1 \%)$. No study participant with vitamin B12 deficiency had the classical findings of macrocytosis, ovalocytosis and hyper segmented WBCs on peripheral blood film assessment (Table 4 summarizes the laboratory findings of the study participants in association with vitamin B12 levels at bivariable analysis).

Factors significantly associated with vitamin B12 levels at multivariable analysis

At multivariable analysis, the statistically significant factors associated with vitamin B12 deficiency were: hemoglobin concentration $<12$ g/dl (adjusted OR-3.38; $95 \%$ CI 1.38$8.31, p$ vaue $=0.008)$ and glycated hemoglobin $\geq 7 \%$ (adjusted OR-3.29; $95 \%$ CI 1.44-7.51, $p$ vaue $=0.005$ ), as summarised in Table 5.

\section{Discussion}

Burden of vitamin B12 deficiency

To our knowledge, this is the first study to describe the burden of vitamin B12 deficiency and its associated factors in adult individuals with diabetes in sub Saharan Africa, a region with a high frequency of nutritional deficiencies $[9,10]$. In this cross sectional study, we report a prevalence of vitamin B12 deficiency of $10.7 \%$ among adult individuals with diabetes attending the outpatient diabetic clinic of Mulago national referral and teaching hospital in Uganda. Haemoglobin concentration $<12 \mathrm{~g} / \mathrm{dl}$ and glycated hemoglobin $\geq 7 \%$ were noted to be independently associated with vitamin B12 deficiency.

Varied prevalence of vitamin B12 deficiency in adult individuals with diabetes has been described by studies performed in different countries outside Africa [2-4, 6, 11-13]. In comparison to the findings in our study, higher frequencies of vitamin B12 deficiency have been reported in U.S. and European studies. A cross sectional 
Table 3 Vitamin B12 deficiency in relation to clinical characteristics at bivariable analysis

\begin{tabular}{|c|c|c|c|c|}
\hline Characteristic & & $\begin{array}{l}<200 \mathrm{pg} / \mathrm{ml}, \\
n(\%)\end{array}$ & $\begin{array}{l}\geq 200 \mathrm{pg} / \mathrm{ml}, \\
n(\%)\end{array}$ & $P$ value \\
\hline \multirow[t]{2}{*}{ Paraesthesias } & No & $4(13.3)$ & 49 (19.6) & 0.621 \\
\hline & Yes & $26(86.7)$ & $201(80.4)$ & \\
\hline \multirow[t]{2}{*}{ Forgetfulness } & No & $28(93.3)$ & $228(91.2)$ & $>0.999$ \\
\hline & Yes & $2(6.7)$ & $22(8.8)$ & \\
\hline \multirow[t]{2}{*}{ Tiredness } & No & $30(100)$ & $236(94.4)$ & 0.376 \\
\hline & Yes & $0(0.0)$ & $14(5.6)$ & \\
\hline \multirow[t]{2}{*}{ Gait } & No & $27(90.0)$ & $242(96.8)$ & 0.101 \\
\hline & Yes & $3(10.0)$ & $8(3.2)$ & \\
\hline \multirow[t]{2}{*}{ Irritability } & No & $29(96.7)$ & 238 (95.6) & $>0.999$ \\
\hline & Yes & $1(3.3)$ & $11(4.4)$ & \\
\hline \multirow[t]{2}{*}{ Pallor } & No & $28(93.3)$ & 244 (98.6) & 0.207 \\
\hline & Yes & $2(6.7)$ & $6(2.4)$ & \\
\hline \multirow[t]{2}{*}{ Hypertension } & No & $9(30.0)$ & $82(32.8)$ & 0.757 \\
\hline & Yes & $21(70.0)$ & $168(67.2)$ & \\
\hline \multirow[t]{2}{*}{ HIV } & No & 28 (93.3) & $235(94.0)$ & 0.701 \\
\hline & Yes & $2(6.7)$ & $15(6.0)$ & \\
\hline \multirow{2}{*}{$\begin{array}{l}\text { Family history of } \\
\text { DM }\end{array}$} & No & $12(40.0)$ & $81(32.4)$ & 0.404 \\
\hline & Yes & $18(60.0)$ & 169 (67.6) & \\
\hline \multirow{2}{*}{$\begin{array}{l}\text { Family history of } \\
\text { HT }\end{array}$} & Yes & $10(33.3)$ & $68(27.4)$ & 0.496 \\
\hline & No & $20(66.7)$ & 180 (72.6) & \\
\hline \multirow{6}{*}{$\begin{array}{l}\text { Current } \\
\text { medication }\end{array}$} & Metformin alone & 7 (23.3) & $41(16.4)$ & 0.726 \\
\hline & Metformin \& SU & $12(40.0)$ & 78 (31.2) & \\
\hline & $\begin{array}{l}\text { Metformin \& SU } \\
\text { \& Pio }\end{array}$ & $1(3.3)$ & $9(3.6)$ & \\
\hline & Insulin alone & $6(20.0)$ & $68(27.2)$ & \\
\hline & $\begin{array}{l}\text { Insulin \& } \\
\text { metformin }\end{array}$ & $4(13.3)$ & $50(20.0)$ & \\
\hline & Statins & $0(0.0)$ & $4(1.6)$ & \\
\hline \multirow{3}{*}{$\begin{array}{l}\text { Age at diagnosis } \\
\text { (years) }\end{array}$} & $<40$ & $8(26.7)$ & 98 (39.2) & 0.144 \\
\hline & $40-60$ & $21(70.0)$ & $129(51.6)$ & \\
\hline & $>60$ & $1(3.3)$ & $23(9.2)$ & \\
\hline \multirow{4}{*}{$\begin{array}{l}\text { Duration since } \\
\text { diagnosed (years) }\end{array}$} & $<2$ & $7(23.3)$ & 59 (23.6) & 0.234 \\
\hline & $2-4$ & $6(20.0)$ & $85(34.0)$ & \\
\hline & $5-7$ & $3(10.0)$ & $32(12.8)$ & \\
\hline & $>7$ & $14(46.7)$ & 74 (29.6) & \\
\hline \multirow[t]{4}{*}{ BMI Kg/m² } & $<18.5$ & $2(6.7)$ & $18(7.2)$ & 0.939 \\
\hline & $18.5-24.9$ & 10 (33.3) & 96 (38.6) & \\
\hline & $25.0-29.9$ & 10 (33.3) & 71 (28.5) & \\
\hline & $\geq 30.0$ & $8(26.7)$ & $64(25.7)$ & \\
\hline \multirow{2}{*}{$\begin{array}{l}\text { Blood pressure } \\
(\mathrm{mmHg})\end{array}$} & $\leq 140 / 80$ & $11(36.7)$ & $115(46.0)$ & 0.332 \\
\hline & $>140 / 80$ & 19 (63.3) & $135(54.0)$ & \\
\hline \multirow{2}{*}{$\begin{array}{l}\text { Metformin alone } \\
(N=48)\end{array}$} & $\leq 3$ years & $4(57.1)$ & 27 (65.9) & 0.657 \\
\hline & $>3$ years & $3(42.9)$ & $14(34.2)$ & \\
\hline
\end{tabular}

Table 3 Vitamin B12 deficiency in relation to clinical characteristics at bivariable analysis (Continued)

\begin{tabular}{lllll}
\hline Metformin \& SU & $\leq 3$ years & $5(41.7)$ & $41(52.6)$ & 0.484 \\
$(N=90)$ & $>3$ years & $7(58.3)$ & $37(47.4)$ & \\
Insulin alone & $\leq 3$ years & $5(83.3)$ & $32(47.1)$ & 0.124 \\
$(N=74)$ & $>3$ years & $1(16.7)$ & $36(52.9)$ & \\
\hline
\end{tabular}

Abbreviations: DM diabetes mellitus, $H T$ hypertension, $B M I$ body mass index, SU sulphonylurea, Pio pioglitazone, PPIs proton pump inhibitors

study by Pflipsen et al. involving 203 outpatient type 2 diabetic patients at a large military primary care clinic in USA documented a prevalence of definite vitamin B12 deficiency of $22 \%$ [2]. Similar studies done in Europe have reported prevalence of about $27 \%[12,13]$.

The apparently higher prevalence in the European and American studies compared to ours was likely at least in part because of differential cut-offs for categorizing deficient vitamin B12 levels. The study by Pflipsen et al. performed in the USA defined definite vitamin B12 deficiency as serum vitamin $B 12$ concentrations of $<100 \mathrm{pg} / \mathrm{ml}$ or elevated serum methylmalonic acid of $>243 \mathrm{nmol} / \mathrm{L}$ or homocysteine concentrations of $>11.9 \mathrm{nmol} / \mathrm{L}$ if serum vitamin B12 concentrations were between 100 and $350 \mathrm{pg} / \mathrm{mL}$ [2]. Therefore, the prevalence in this study would have been higher using a similar cut off $<200 \mathrm{pg} / \mathrm{ml}$.

Differential prevalence rates of vitamin B12 deficiency could also be due to genetic influences and differences in dietary intake (low dietary intake of foods rich in vitamin B12 like meat).

Comparable prevalence of vitamin B12 deficiency of 9.5-14.2\% has been reported in similar studies among South Korean [3, 11] and Indian [12] adult individuals with diabetes. However, despite the comparable prevalence noted in the South Korean studies [3, 11], different study definitions of vitamin B12 deficiency were used (serum vitamin B12 levels $\leq 300 \mathrm{pg} / \mathrm{mL}$ without folate deficiency).

In Uganda, the burden of vitamin B12 deficiency has previously been studied in 2 patient populations: psychiatric patients who had a prevalence rate of $28.6 \%$ [14] and outpatient HIV infected patients who had a prevalence rate of $10.3 \%$ [15]. The study in psychiatric patients defined vitamin B12 deficiency as serum vitamin B12 levels $<240 \mathrm{pg} / \mathrm{ml}$ which likely accounted for the apparently higher rates compared to our study of diabetic outpatients.

\section{Factors associated with vitamin B12 deficiency at bivariable and multivariable analysis}

At bivariable analysis, a statistically significant association with vitamin B12 deficiency was observed with hemoglobin level $<12 \mathrm{~g} / \mathrm{dl}$, glycated hemoglobin $\geq 7 \%$ and WBC count. However, at multivariable analysis, hemoglobin level and glycated hemoglobin retained statistical significance. 
Table 4 Vitamin B12 deficiency in relation to laboratory findings at bivariable analysis

\begin{tabular}{|c|c|c|c|c|}
\hline Characteristic & & $\begin{array}{l}<200 \mathrm{pg} / \mathrm{ml} \\
n(\%)\end{array}$ & $\begin{array}{l}\geq 200 \mathrm{pg} / \mathrm{ml} \\
n(\%)\end{array}$ & $P$ value \\
\hline \multirow[t]{2}{*}{ Haemoglobin, g/dl } & $\geq 12.0$ & $18(60.0)$ & $211(84.4)$ & 0.001 \\
\hline & $<12.0$ & $12(40.0)$ & $39(15.6)$ & - \\
\hline \multirow[t]{2}{*}{ WBC count, cells $/ \mathrm{mm}^{3}$} & $<4$ & $5(16.7)$ & $13(5.3)$ & 0.017 \\
\hline & $\geq 4$ & $25(83.3)$ & $234(94.7)$ & - \\
\hline \multirow[t]{3}{*}{ Mean cell volume, fl } & $<79.9$ & $10(34.5)$ & $63(25.6)$ & 0.186 \\
\hline & 80-99.9 & $18(62.1)$ & $181(73.3)$ & - \\
\hline & $\geq 100$ & $1(3.4)$ & $3(1.2)$ & - \\
\hline \multirow{2}{*}{$\begin{array}{l}\text { Red cell distribution } \\
\text { width, \% }\end{array}$} & $<17$ & $29(96.7)$ & $246(98.8)$ & 0.367 \\
\hline & $\geq 17$ & $1(3.3)$ & $3(1.2)$ & - \\
\hline \multirow[t]{2}{*}{ FBS level, $\mathrm{mmol} / \mathrm{l}$} & $<7$ & $9(30.0)$ & $62(25.2)$ & 0.570 \\
\hline & $\geq 7$ & $21(70.0)$ & $184(74.8)$ & - \\
\hline \multirow[t]{2}{*}{$\mathrm{HbA} 1 \mathrm{c}, \%$} & $<7$ & $16(53.3)$ & $59(23.7)$ & 0.001 \\
\hline & $\geq 7$ & $14(46.7)$ & $190(76.3)$ & - \\
\hline \multirow[t]{2}{*}{ LDLC, mmol/l } & $<2.6$ & $8(26.7)$ & $59(24.1)$ & 0.756 \\
\hline & $\geq 2.6$ & $22(73.3)$ & $186(75.9)$ & - \\
\hline \multirow[t]{2}{*}{$\mathrm{TGL}, \mathrm{mmol} / \mathrm{l}$} & $<1.7$ & $16(53.3)$ & $106(43.3)$ & 0.295 \\
\hline & $\geq 1.7$ & $14(46.7)$ & $139(56.7)$ & - \\
\hline \multirow[t]{2}{*}{ Total cholesterol, mmol/l } & $<5$ & $14(46.7)$ & $128(51.6)$ & 0.594 \\
\hline & $\geq 5$ & $16(53.3)$ & $119(48.2)$ & - \\
\hline \multirow[t]{2}{*}{$\mathrm{HDLC}, \mathrm{mmol} / \mathrm{l}$} & $<1$ & $11(36.7)$ & $62(25.3)$ & 0.183 \\
\hline & $\geq 1$ & $19(63.3)$ & $183(74.7)$ & - \\
\hline \multirow[t]{2}{*}{ Serum creatinine, $\mu \mathrm{mol} / \mathrm{l}$} & $<125$ & $28(93.3)$ & $236(96.3)$ & 0.342 \\
\hline & $\geq 125$ & $2(6.7)$ & $9(3.7)$ & - \\
\hline \multirow[t]{2}{*}{ Serum urea, $\mathrm{mmol} / \mathrm{l}$} & $<6.5$ & 28 (96.6) & $219(90.9)$ & 0.486 \\
\hline & $\geq 6.5$ & $1(3.5)$ & $22(9.1)$ & - \\
\hline \multirow[t]{2}{*}{$A L T, U / L$} & $<60$ & $30(100)$ & 245 (99.6) & $>0.999$ \\
\hline & $\geq 60$ & $0(0)$ & $1(0.4)$ & - \\
\hline \multirow[t]{2}{*}{ AST, U/L } & $<60$ & $27(93.1)$ & $243(99.2)$ & 0.057 \\
\hline & $\geq 60$ & $2(6.9)$ & $2(0.8)$ & - \\
\hline \multirow[t]{2}{*}{ Albumin, g/L } & $<35$ & $2(6.7)$ & $15(6.1)$ & $>0.999$ \\
\hline & $\geq 35$ & $28(93.3)$ & $232(93.9)$ & - \\
\hline \multirow[t]{2}{*}{ HIV serology } & No & $28(93.3)$ & $232(94.3)$ & 0.688 \\
\hline & Yes & $2(6.7)$ & $14(5.7)$ & - \\
\hline
\end{tabular}

Abbreviations: WBC white blood cell, FBS fasting blood sugar, HbA1c glycated haemoglobin, LDLC low density lipoprotein cholesterol, TGL triglycerides, HDLC high density lipoprotein cholesterol, ALT alanine transaminases, AST aspartate transaminases, HIV human immunodeficiency virus

Hematological derangements presenting either as a lone cytopenia or pancytopenia are a common finding in patients with vitamin B12 deficiency. Vitamin B12 is an essential micronutrient required in DNA synthesis, cellular repair and optimal haemopoesis together with other micronutrients like folate and iron. In addition to pancytopenia, other overt hematological findings like macrocytic
Table 5 Unadjusted and adjusted odds ratios for predictors of B12 deficiency using a logistic regression

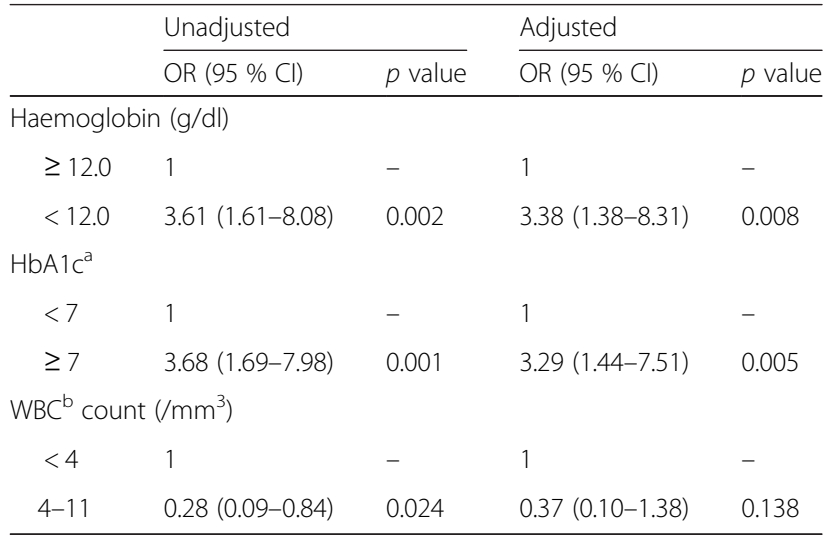

Controlled for age and gender variables

${ }^{\mathrm{a} H b A 1 c-g l y c a t e d ~ h a e m o g l o b i n}$

${ }^{b}$ WBC-White blood cell

red blood cells (mean cell volume $[\mathrm{MCV}]>100 \mathrm{fl}$ ) with/ without anemia, ovalocytes and hyper segmented white blood cells (i.e. $>5 \%$ of neutrophils with $\geq 5$ lobes) are also very frequent. However, these hematological derangements are usually preceded by neurological manifestations like irritability, gait disturbances and paraesthesias $[1,16]$, which were highly prevalent in our study population.

Contradictorily, raised MCV levels were uncommon among the participants with vitamin B12 deficiency in our study. This could be due to the high prevalence of co-existing iron deficiency anemia in SSA arising from poor dietary intake and helminth infestation [10]. We did not however perform a comprehensive dietary assessment, serum ferritin level measurement and stool examination for ova and cysts in this study.

\section{Glycated hemoglobin and vitamin B12 deficiency}

Glycated haemoglobin level $\geq 7 \%$ which reflects suboptimal glucose control in adult individuals with diabetes was associated with vitamin B12 deficiency in this study population. Compelling evidence from several studies have associated vitamin B12 deficiency and accompanying hyperhomocysteinemia with increased oxidative stress and insulin resistance which collectively result into suboptimal glycaemic control [17-19]. Studies have also demonstrated that low maternal vitamin B12 levels in early pregnancy are often associated with offspring insulin resistance and future DM $[20,21]$. The speculative mechanism to explain this is epigenetic modifications due to absence of methionine, a ubiquitous 1-carbon donor to numerous methylation reactions, including DNA methylation. This contributes to elevation in insulin resistance as has been suggested in animal models [22].

Other studies have demonstrated a close association between vitamin B 12 deficiency and long term use and high dose metformin therapy [3-6, 11, 13, 23]. Metformin 
has been shown to reduce calcium bioavailability which affects ileal vitamin B12 absorption [1, 24]. In our study, this association was not observed probably because there were few patients on metformin therapy.

\section{Study limitations}

The diagnosis of vitamin B12 deficiency is best assessed using levels of serum homocysteine and methylmalonic acid which helps identify patients with borderline (low normal) levels. Unfortunately, we were unable to perform these tests because they are not readily available in Uganda. The study was performed from a single study site or urban hospital based. Therefore, these results cannot be extrapolated to other hospitals and the general nonclinical population at a national level. Finally, the crosssectional design could not establish a cause-effect relationship between vitamin B12 deficiency and other clinical factors such as diabetes control. Even though more numbers of study participants were enrolled than the desired number, the study still faces a limitation of small sample size particularly in some of the individual cell sizes.

\section{Conclusions}

Vitamin B12 deficiency occurs in approximately 1 in 10 of adult ambulatory individuals with diabetes receiving care in a Ugandan national referral hospital. Low hemoglobin concentrations $<12 \mathrm{~g} / \mathrm{dl}$ and elevated glycated hemoglobin levels $\geq 7 \%$ (suboptimal glycaemic control) were associated with vitamin B12 deficiency. Elevated MCV levels and red blood cell changes like macrocytosis and hyper segmented WBCs were not as prevalent as expected in patients with vitamin B12 deficiency. Given the relatively high rates and known potential problems associated with vitamin B12 deficiency, we recommend screening for all adult individuals with diabetes, especially in those with suboptimal diabetes control and anemia. We also recommend a prospective representative multi-centre study to assess the prevalence of vitamin B12 deficiency in individuals without diabetes as controls compared to those with diabetes and to examine the effect of vitamin B12 deficiency on optimal glycaemic control and worsening of insulin resistance among individuals with diabetes.

\section{Acknowledgement}

We would like to deeply appreciate Dr. Richard Ssekitoleko for his invaluable contribution towards the development of this manuscript and all the patients who accepted to participate in this study.

\section{Study funding}

This study was supported by the National Institute of Neurological Disorders and Stroke of the National Institute of Health under MEPI-Neurology linked award number R25NS080968. The funding body did not participate in the design of the study and collection, analysis, and interpretation of data and in writing the manuscript.

\section{Availability of data and materials}

The data supporting these findings is available in form of an excel file and will be shared once requested.
Authors' contributions

GPA, DK, MK, CO, RL, EM and MS contributed to the conception and design of the research, GPA contributed to the acquisition of the data, GPA, DK, LM, $M K, C O, R L, E M$ and $M S$ equally contributed to the analysis and interpretation of data. All authors drafted the manuscript, critically revised the manuscript and read and approved the final manuscript.

\section{Competing interests}

None of the authors has any conflict of interest.

\section{Ethics approval and consent to participate}

Ethical approval for this study was obtained from the Institutional Review Board (IRB) of the Makerere University College of Health Sciences and the department of medicine, Makerere University Uganda. All study participants provided written informed consent to participate in this study.

\section{Author details}

'Department of Medicine, Makerere University College of Health Sciences, P.O.BOX 7062, Kampala, Uganda. ${ }^{2}$ Department of Medicine/Diabetic and Hypertension Clinics, Our Lady of Consolata Hospital Kisubi, Wakiso, Uganda. ${ }^{3}$ Infectious Disease Research Collaboration, Kampala, Uganda. ${ }^{4}$ Diabetes/ Endocrine Unit, Mulago National Referral and Teaching Hospital, Kampala, Uganda. ${ }^{5}$ Department of Neurology, Case Western Reserve University and University Hospitals Case Medical Center, Cleveland, OH, USA.

Received: 9 February 2016 Accepted: 20 July 2016

Published online: 26 July 2016

\section{References}

1. Kibirige D, Mwebaze R. Vitamin B12 deficiency among patients with diabetes mellitus: is routine screening and supplementation justified? J Diabetes Metab Dis. 2013;12:17.

2. Pflipsen M, Oh R, Saguil A, Seehusen D, Topolski R. The prevalence of vitamin B12 deficiency in patients with type 2 diabetes: a cross-sectional study. J Am Board Fam Med. 2009;22:528-34.

3. Kang D, Yun J, Ko S, Lim T, Ahn Y, Park Y, et al. Higher prevalence of metformin-induced vitamin B12 deficiency in sulfonylurea combination compared with insulin combination in patients with type 2 diabetes: a cross-sectional study. PLoS ONE. 2014;9(10):e109878.

4. Ting R, Szeto C, Chan M, Ma K, Chow K. Risk factors of vitamin B12 deficiency in patients receiving metformin. Arch Intern Med. 2006;166:1975-9.

5. Niafar M, Hai F, Porhomayon J, Nader N. The role of metformin on vitamin B12 deficiency: a meta-analysis review. Intern Emerg Med. 2015;10(1):93-102.

6. De-Jager J, Kooy A, Lehert $P$, et al. Long term treatment with metformin in patients with type 2 diabetes and risk of vitamin B-12 deficiency: randomised placebo controlled trial. BMJ. 2010;340:c2181.

7. Malouf R, Areosa S. Vitamin B12 for cognition. Cochrane Database of Systematic Reviews. 2003. (3):CD 004326.

8. Güzelcan Y, Van-Loon P. Vitamin B12 status in patients of Turkish and Dutch descent with depression: a comparative cross-sectional study. Ann General Psychiatry. 2009;8:18

9. Khan $Y$, Bhutta Z. Nutritional deficiencies in the developing world: current status and opportunities for intervention. Pediatr Clin North Am. 2010;57(6):1409-41.

10. Phiri K. Approaches to treating chronic anemia in developing countries. Transfus Alter Transfus Med. 2008;10(2):75-81.

11. Ko S, Ko S, Ahn Y, Song K, Han K, Park Y, et al. Association of vitamin B12 deficiency and metformin use in patients with type 2 diabetes. J Korean Med Sci. 2014;29:965-72.

12. Adaikalakoteswari $A$, Jayashri $R$, Sukumar $N$, Venkataraman $H$, Pradeepa $R$, Gokulakrishnan K, et al. Vitamin B12 deficiency is associated with adverse lipid profile in Europeans and Indians with type 2 diabetes. Cardiovasc Diabetol. 2014;13:129.

13. Hermann L, Nilsson B, Wettre S. Vitamin B12 status of patients treated with metformin: a cross-sectional cohort study. Br J Diabetes Vasc Dis. 2004;4:401.

14. Ssonko M, Ddungu $H$, Musisi S. Low serum vitamin B12 levels among psychiatric patients admitted in butabika mental hospital in Uganda. BMC Res Notes. 2014;7:90

15. Semeere A, Nakanjako D, Ddungu H, Kambugu A, Manabe Y, Colebunders R. Sub-optimal vitamin B-12 levels among ART-naive HIVPositive individuals in an urban cohort in Uganda. PLoS One. 2012;7(7), e40072. 
16. Aslinia F, Mazza J, Yale S. Megaloblastic anemia and other causes of macrocytosis. Clin Med Res. 2006;:236-41.

17. Meigs J, Jacques P, Selhub J, Singer D, Nathan D, Rifai N, et al. Fasting plasma homocysteine levels in the insulin resistance syndrome: the Framingham offspring study. Diabetes Care. 2001;24:1403-10.

18. Giltay E, Hoogeveen E, Elbers J, Gooren L, Asscheman H, Stehouwer C. Insulin resistance is associated with elevated plasma total homocysteine levels in healthy, non-obese subjects. Atherosclerosis. 1998;139:197-8.

19. Ho M, Halim J, Gow M, El-Haddad N, Marzulli T, Baur L. Vitamin B12 in obese adolescents with clinical features of insulin resistance. Nutrients. 2014:6:5611-8.

20. Stewart C, Christian P, Schulze K, Arguello M, Leclerq S, Khatry S. Low maternal vitamin B-12 status is associated with offspring insulin resistance regardless of antenatal micronutrient supplementation in rural Nepal. J Nutr. 2011:141:1912-7.

21. Saravanan $\mathrm{P}$, Yajnik C. Role of maternal vitamin B12 on the metabolic health of the offspring: a contributor to the diabetes epidemic? Br J Diabetes Vasc Dis. 2010;10:109-14.

22. Cooney C, Dave A, Wolff G. Maternal methyl supplements in mice affect epigenetic variation and DNA methylation of offspring. J Nutr. 2002;132(8):S2393-400.

23. Biemans E, Hart HE, Rutten GE, Cuellar Renteria VG, Kooijman-Buiting AM, Beulens JW. Cobalamin status and its relation with depression, cognition and neuropathy in patients with type 2 diabetes mellitus using metformin. Acta Diabetol. 2015;52(2):383-93.

24. Bauman W, Shaw S, Jayatilleke E, Spungen A, Herbert V. Increased intake of calcium reverses vitamin B12 malabsorption induced by metformin. Diabetes Care. 2000;23:1227-31.

\section{Submit your next manuscript to BioMed Central} and we will help you at every step:

- We accept pre-submission inquiries

- Our selector tool helps you to find the most relevant journal

- We provide round the clock customer support

- Convenient online submission

- Thorough peer review

- Inclusion in PubMed and all major indexing services

- Maximum visibility for your research

Submit your manuscript at www.biomedcentral.com/submit

) Biomed Central 